\title{
Pengenalan Jenis Kupu-kupu pada Murid SD 129 INPRES Kecamatan Bantimurung, Kabupaten Maros Sulawesi Selatan
}

\author{
Sri Nur Aminah Ngatimin ${ }^{1, *}$, Tamrin Abdullah², Andi Nasruddin², dan Ahdin Gassa² \\ ${ }^{1}$ Staf Pengajar Fakultas Pertanian Universitas Hasanuddin, Makassar \\ ${ }^{2}$ Staf Pengajar Fakultas Pertanian Universitas Hasanuddin \\ *E-mail: srifirnas@gmail.com
}

\begin{abstract}
The aim of research is to identification butterflies species at Pattunuang Resort and increased knowledge of Elementary School students about the roles of insects as pollinators and main part of biodiversity in nature. The research as a survey was conducted in Pattunuang Resort and SDN 129 Inpres Bantimurung Regency, Maros District from March to May 2017. The steps of research was: 1) build transect lines for butterflies observation; 2) butterfly identification and counting of their population used Shannon-Wiener Index Biodiversity, then 3) introducing butterflies species to Elementary School students Class Five at SDN 129 Inpres Bantimurung. The result was showed, we find 20 individual butterflies from 6 species of Papilionids (Troides haliphron, T. helena, Papilio demoleus, P. demolion and Graphium agamemnon), also Danaus chrysippus from Nymphalids. Based value of Shannon-Wiener Index, we find very low criteria of butterflies $(H<1)$. The conclusion : 1) findings of 20 butterflies individual from 6 species (Papilionids and Nymphalids); 2) approximately $57.3 \%$ of Elementary School students recognized butterflies species and 3) $28.8 \%$ from them as a butterflies wild hunter. Recommendation for the future, we need more collaborative research and development from University and local government increasing introducing butterflies conservation species for Elementary School students around Pattunuang Resort.
\end{abstract}

Keywords: butterflies; pattunuang; Papilionids; Nymphalids

DOI: $10.24259 / j h m . v 9 i 1.1975$

\section{PENDAHULUAN}

Kabupaten Maros merupakan salah satu habitat kupu-kupu yang ideal dan terletak di Provinsi Sulawesi Selatan. Resort Pattunuang merupakan suatu daerah yang termasuk dalam kawasan Taman Nasional Bantimurung Bulusaraung. Pegunungan karst merupakan sumberdaya alam yang tidak terbarukan dan menjadi ekosistem yang sangat penting dalam menunjang proses berkembangbiaknya jenis fauna tertentu utamanya kupu-kupu. Pentingnya menjaga kelestarian kawasan karst karena berperan sebagai penyimpan dan pengatur tata air. Saat ini diperkirakan 15\% kawasan karst dunia mencukupi sekitar 25\% kebutuhan air bersih penduduk dunia (Amran, 2002).

Resort Pattunuang di Kabupaten Maros merupakan habitat berbagai jenis kupu-kupu yang hidup di daerah tersebut. Secara geografis, kawasan ini terletak antara $119^{\circ} 42^{\prime} 57^{\prime \prime}-119^{\circ} 45^{\prime} 00^{\prime \prime}$ Bujur Timur dan $5^{\circ} 31^{\prime} 08^{\prime \prime}-5^{\circ} 33^{\prime} 42^{\prime \prime}$ Lintang Selatan. Secara administratif pemerintahan terletak di Kecamatan Simbang Kabupaten Maros (Dishut, 2003). Pertambahan penduduk menyebabkan meningkatnya kebutuhan sandang, pangan dan papan karena alih fungsi hutan menjadi lahan pertanian dan pemukiman. Perubahan habitat dan kekurangan makanan menyebabkan terjadinya migrasi kupu-kupu menuju daerah yang jauh dari gangguan manusia.

Beberapa jenis kupu-kupu yang terdapat di TWA Gua Pattunuang dilindungi dalam Peraturan Pemerintah Nomor 7 Tahun 1999 yakni : Troides haliphron Boisduval, Troides helena Linnaeus dan Troides hypolithus Rotschild dari famili Papilionidae. Satu jenis lainnya adalah Cethosia myrina (kupu-kupu bidadari) dari famili Nymphalidae sudah sangat jarang ditemukan (Dishut, 2003). 
Berdasarkan pemanfaatan satwa secara legal, sejak tahun 1992 perdagangan kupu-kupu Indonesia telah dilakukan secara formal (Pustekkom, 2005; Soehartono dan Mardiastuti, 2002). Keindahan bentuk dan warna sayap kupu-kupu Bantimurung membuat nilai ekonomisnya tinggi sehingga timbul permintaan konsumen yang menginginkan jenis kupu-kupu tertentu. Sri et al., (2014a dan 2015) melaporkan bahwa setiap jenis kupu-kupu di kawasan Bantimurung muncul pada waktu yang berbeda, contohnya Kupu-kupu Raja $T$. helena famili Papilionidae yang tampak di bulan Januari sampai Maret di Taman Nasional Bantimurung Bulusaraung. Jenis T. helena termasuk dalam jenis kupu-kupu dilindungi dalam PP Nomor 7 Tahun 1999 dan CITES Appendix 2. Kupu-kupu tersebut hidup dengan mengkonsumsi nektar gulma berbunga Lantana camara dan orok-orok (Crotalaria striata). Sri dan Syatrawati (2014b) telah melakukan survei di Resort Pattunuang dan menemukan bahwa kupu-kupu Graphium androcles Boisduval adalah jenis yang tidak dilindungi tetapi populasinya sudah sangat menurun dan berada di ambang kepunahan. Perburuan liar karena kurangnya pengetahuan masyarakat tentang konservasi alam juga merupakan salah satu pemicu terjadinya penurunan populasi kupu-kupu yang sangat cepat. Saat ini hampir semua kupu-kupu yang hidup di kawasan Bantimurung berada dalam status terancam punah dan harus segera dilakukan tindakan konservasi.

Murid sekolah dasar sebagai salah satu generasi penerus cita-cita bangsa merupakan aset yang sangat berharga dalam upaya pelestarian kupu-kupu. Berdasarkan pengamatan penulis, kebanyakan penangkap kupu-kupu Bantimurung adalah murid sekolah dasar. Kegiatan menangkap kupu-kupu umumnya dilakukan setelah pulang sekolah. Lokasi perburuannya adalah hutan sekunder yang terdapat di kawasan Bantimurung. Hasil tangkapan tersebut digunakan untuk membeli kebutuhan sehari-hari (Sri, unpublished).

Berdasarkan fakta yang telah dikemukakan, dipandang perlu untuk melakukan kegiatan tentang pengenalan jenis kupu-kupu pada murid SD khususnya yang bersekolah di SD 129 Inpres Bantimurung Kabupaten Maros. Diharapkan kegiatan ini dapat memberikan pemahaman sejak dini tentang jenis kupu-kupu dan peranannya di alam.

\section{METODOLOGI PENELITIAN}

Penelitian ini telah dilaksanan sejak bulan Maret sampai Mei 2017 yang bertempat di Resort Pattunuang, Taman Nasional Bantimurung Bulusaraung Kabupaten Maros. Populasi pada penelitian ini adalah kupu-kupu yang ada di Resort Pattunuang. Penelitian ini berbentuk survei dan mengadakan penyuluhan tentang pengenalan jenis kupu-kupu untuk murid SD 129 Inpres Bantimurung Kabupaten Maros.

\subsection{Bahan dan Alat Penelitian}

Adapun bahan yang digunakan dalam penelitian adalah : peta Resort Pattunuang, kupu-kupu dan tumbuhan pakannya. Alat yang digunakan adalah : lup, alat tulis menulis, papan pengalas, parang, gunting, tali transek, gunting, pisau dan kamera digital.

\subsection{Tahapan Pelaksanaan}

\subsubsection{Pemasangan Transek dan Pengamatan Jenis Kupu-kupu}

Metode yang digunakan untuk kegiatan inventarisasi dan identifikasi jenis kupu-kupu adalah survei. Teknis pelaksanaan menggunakan sistem transek (Pellet et al., 2012) sepanjang 500 meter untuk pengambilan data. Transek tersebut dibuat sejajar dengan arah aliran sungai. Kondisi lapangan yang dipilih untuk pengamatan kupu-kupu fokus pada daerah yang ditumbuhi tumbuhan pakan (untuk kupu-kupu dan larvanya) serta jalur aliran sungai. Pengamatan jenis kupu-kupu dilakukan selama sekali seminggu pada saat cuaca cerah antara jam 08.00 - 11.00 WITA dengan memperhatikan waktu aktif serangga. Salmah, dkk,. 
(2002) menyatakan bahwa sebagai serangga diurnal, kupu-kupu aktif saat pagi hari pukul $09.00-11.00$ WIB dan sore harinya 14.00 - 16.00 WIB. Pada setiap jarak 50 meter dilakukan pengamatan intensif selama 5 menit untuk mengambil dokumentasi jenis kupu-kupu yang aktif pada saat itu. Dicatat pula jenis tanaman inang yang ditemukan di sepanjang jalur pengamatan.

\subsubsection{Identifikasi Kupu-kupu}

Identifikasi kupu-kupu dilakukan berdasarkan dokumentasi yang dilakukan saat pengamatan. Proses identifikasi kupu-kupu menggunakan buku acuan Kristensen et al. (1991), Braby (2000), Dishut (2003), Salmah, Abbas dan Dahelmi (2002), Peggie dan Amir (2006), Peggie (2011) dan Peggie (2014). Untuk identifikasi jenis tanaman inang kupu-kupu menggunakan literatur Soerjani, Kostermans dan Tjitrosoepomo (1987), van Steenis (1988) serta Salmah, Abbas dan Dahelmi (2002).

\subsubsection{Parameter Jenis Kupu-kupu}

Parameter yang diamati dalam kegiatan ini adalah keanekaragaman jenis kupu-kupu dengan menggunakan Indeks Keanekaragaman Shannon-Wiener (Odum, 1998) dengan rumus :

$$
\mathrm{H}^{\prime}=-\sum_{i=1}^{s} \text { pi Ln pi }
$$

$$
\begin{array}{ll}
\mathrm{H}^{\prime} & =\text { Indeks keanekaragaman jenis kupu-kupu } \\
\mathrm{Pi} & =\text { ni/N } \\
\mathrm{ni} & =\text { Jumlah individu jenis ke-i } \\
\mathrm{N} & =\text { Total individu }
\end{array}
$$

Kriteria untuk nilai indeks keanekaragaman Shannon-Wiener menggunakan kriteria yang telah dimodifikasi oleh Suana (2007) sebagai berikut :

\begin{tabular}{|c|c|}
\hline Nilai Indeks Shannon-Wiener & Tingkat Keanekaragaman \\
\hline $\mathrm{H}<1$ & Sangat rendah \\
\hline $1<\mathrm{H}<2$ & Rendah \\
\hline $2<\mathrm{H}<3$ & Sedang \\
\hline $3<\mathrm{H}<4$ & Tinggi \\
\hline $\mathrm{H}<4$ & Sangat tinggi \\
\hline
\end{tabular}

\subsubsection{Pengenalan Jenis Kupu-kupu di Sekolah Dasar}

Pemanfaatan hasil survei kupu-kupu di Resort Pattunuang digunakan sebagai sumber belajar Ilmu Pengetahuan Alam, untuk murid kelas 5 SDN 129 Inpres Bantimurung. Strategi pembelajarannya adalah murid-murid diminta menjawab pertanyaan di dalam kuesioner dan dilanjutkan dengan ceramah interaktif yang 
dilakukan dalam dua kelas masing-masing selama 30 menit. Materi ceramah mencakup jenis kupu-kupu dan cara konservasi sederhana yang mudah untuk dipraktekkan. Materi ceramah berisi bahasa yang mudah dimengerti dan disesuaikan dengan umur anak-anak yang berada dalam kisaran umur $8-11$ tahun. Materi ceramah tersebut dituangkan dalam bentuk poster yang dipasang di dinding sekolah setelah selesai kegiatan.

\section{HASIL DAN PEMBAHASAN}

\subsection{Jenis Kupu-kupu}

Berdasarkan hasil inventarisasi dan identifikasi kupu-kupu yang telah dilakukan di Resort Pattunuang ditemukan 20 individu yang terdiri dari 6 jenis yang semuanya tergolong dalam famili Papilionidae yakni $T$. haliphron, T. helena, P. demoleus, $P$. demolion, G. agamemnon serta $D$. chrysippus dari famili Nymphalidae (Tabel 1).

Tabel 1. Jenis Kupu-kupu yang Ditemukan di Resort Pattunuang

\begin{tabular}{clcccc}
\hline No. & \multicolumn{1}{c}{ Jenis Kupu-kupu } & Total & Rerata & $\mathrm{Pi}$ & $\mathrm{Pi}$ In Pi \\
\hline 1. & T. haliphron & 3 & 1.5 & 0.01 & 0.05 \\
\hline 2. & T. helena & 4 & 2.0 & 0.01 & 0.05 \\
\hline 3. & P. demoleus & 2 & 1.0 & 0.01 & 0.04 \\
\hline 4. & P. demolion & 6 & 3.0 & 0.03 & 0.09 \\
\hline 5. & G. agamemnon & 3 & 1.5 & 0.01 & 0.05 \\
\hline 6. & D. chrysippus & 2 & 1.0 & 0.01 & 0.04 \\
\hline
\end{tabular}

Sumber : data primer yang diolah (2017)

Selama proses pengamatan, beberapa ekor kupu-kupu ditemukan sedang mencari pasangannya di sekitar tumbuhan pakannya (Aristolochia tagala) yakni T. haliphron dan T. helena. Berdasarkan nilai Indeks Shannon-Wiener untuk semua jenis kupu-kupu berada dalam kriteria sangat rendah $(H<1)$. Selain itu, saat pengamatan berlangsung kawasan Bantimurung sedang berada dalam masa peralihan musim hujan ke musim kemarau sehingga diduga adanya perubahan cuaca ikut berkontribusi terhadap kurangnya jenis kupukupu yang diamati.

$T$. haliphron, $T$. helena dan $T$. hypolithus adalah serangga monofag yang makan daun sirih hutan $(A$. tagala). Tumbuhan pakan ini ditemukan banyak merambat di sepanjang aliran sungai tetapi tidak ditemukan adanya larva maupun kepompong. Pada saat pengamatan tidak ditemukan $T$. hypolithus. Tumbuhan pakan yang banyak ditemukan di Resort Pattunuang dan menjadi sumber nektar kupu-kupu adalah kembang sepatu (Hibiscus rosa-chinensis), kembang pagoda (Clerodendrum paniculatum) dan asoka. Tanaman asoka ditemukan tumbuh di pekarangan rumah penduduk. Selain itu terdapat tanaman jeruk (Citrus sp.) yang daunnya dikonsumsi oleh larva $P$. demoleus, $P$. demolion dan $G$. agamemnon. Larva kupu-kupu $D$. chrysippus (famili Nymphalidae) mengkonsumsi tanaman famili Annonaceae, Sapindaceae, Convolvulaceae dan Euphorbiaceae. Peggie dan Amir (2006) menyebutkan bahwa kupu-kupu D. chrysippus senang hidup di tempat terbuka yang berdekatan dengan aliran air. Semua jenis kupu-kupu yang disebutkan merupakan jenis yang mempunyai nilai ekonomis yang diminati oleh wisatawan sehingga dapat menopang kehidupan ekonomi masyarakat yang bermukim di kawasan Bantimurung. 
Menurut Salmah, dkk. (2012) mengemukakan bahwa adanya perbedaan jenis vegetasi tumbuhan pada suatu kawasan sangat menentukan nilai indeks keanekaragaman kupu-kupu yang ditemukan di daerah tersebut. Rendahnya jumlah individu yang ditemukan diduga karena terjadinya perburuan liar sejak lama serta rusaknya habitat kupu-kupu. Saat pengamatan berlangsung sedang dilakukan pembangunan jembatan bypass yang akan menghubungkan Kabupaten Maros dan Kabupaten Bone yang melewati hutan Camba. Penggunaan mesin dan alat berat dalam proses pembangunan tersebut menyebabkan hilangnya tumbuhan pakan dan rusaknya habitat kupu-kupu. Amran (2002) dan Peggie (2011) menyatakan bahwa banyaknya kupu-kupu pada suatu daerah sangat dipengaruhi oleh pola penyebaran dan kesesuaian habitatnya. Tumbuhan pakan kupu-kupu ada dua jenis yakni tumbuhan berbunga yang menyediakan nektar untuk kupukupu (serangga dewasa) dan tumbuhan pakan sebagai makanan larvanya.

\subsection{Pemanfaatan Kupu-kupu Sebagai Sumber Belajar IPA}

Hasil pengisian kuesioner oleh murid kelas 5 SDN 129 Inpres Bantimurung dapat dilihat pada Tabel 2 di bawah ini :

Tabel 2. Hasil Kuesioner Murid Kelas 5 SDN 129 Inpres Bantimurung

\begin{tabular}{clc}
\hline No. & \multicolumn{1}{c}{ Pertanyaan } & Hasil (\%) \\
\hline 1. & Mengenal jenis kupu-kupu & 57.3 \\
\hline 2. & Manfaat kupu-kupu di alam & 34.3 \\
\hline 3. & Profesi sebagai penangkap kupu-kupu & 28.8 \\
\hline 4. & Menjual hasil kupu-kupu tangkapan & 24.7 \\
\hline 5. & Menanam tumbuhan pakan kupu-kupu di pekarangan & 9.6 \\
\hline 6. & Takut/tidak suka kupu-kupu & 6.8 \\
\hline
\end{tabular}

Sumber : Data primer yang diolah (2017)

Berdasarkan hasil kuesioner dapat dilihat bahwa 57.3\% dari murid kelas 5 SDN 129 Inpres Bantimurung telah mengenal jenis kupu-kupu. Melihat dari kuesioner tersebut ada sebanyak $28.8 \%$ dari anakanak tersebut berprofesi sebagai penangkap kupu-kupu yang dilakukan saat pulang dari sekolah. Anak-anak tersebut menjual kupu-kupu hasil tangkapannya dengan harga Rp. 2.000 per ekor kepada pengumpul dan membelanjakan uangnya untuk membeli barang kebutuhan sehari-hari. Fenomena ini merupakan gambaran bahwa kebanyakan masyarakat yang bermukim di sekitar kawasan Bantimurung masih menggantungkan hidupnya dari alam dan mengabaikan konsep konservasi.

Selain itu, hasil penelitian yang diwujudkan dalam bentuk poster memberikan dampak positif terhadap murid SDN 129 Inpres Bantimurung. Murid-murid tersebut sangat antusias menyebut nama berbagai jenis kupu-kupu dalam bahasa daerah contohnya helena, halipron dan hipolitus untuk jenis Troides. Disbun (2003) menyebutkan bahwa $T$. haliphron, $T$. helena dan $T$. hypolithus merupakan jenis kupu-kupu yang dilindungi di Sulawesi Selatan berdasarkan Peraturan Pemerintah Nomor 7 Tahun 1999. Selanjutnya Peggie (2008) menegaskan bahwa penamaan ilmiah hewan dan tumbuhan yang telah ditetapkan oleh Carolus Linnaeus sejak tahun 1758 berlaku baku dan universal bertujuan untuk menyamakan persepsi dan mengacu pada kesamaan jenis individu tertentu. Jadi dapat dikatakan bahwa penggunaan nama lokal kupu-kupu harus disikapi dengan sangat hati-hati.

Resort Pattunuang berada di bawah pengelolaan Kantor Balai Taman Nasional BantimurungBulusaraung. Terdapat sekitar 40 desa di kawasan Taman Nasional Bantimurung-Bulusaraung yang kondisi 
ekonominya masih memprihatinkan. Hal ini menjadi indikator bahwa aksesibilitas penduduk terhadap Resort Pattunuang dan kawasan konservasi lainnya membuat masyarakat sangat tergantung dari alam. Hal ini menjadi tantangan bagi Pemerintah Daerah Kabupaten Maros bagaimana masyarakat menjadi bagian dari pengelolaan kawasan hutan yang tetap mendukung kelestarian habitat kupu-kupu yang bermukim di dalamnya.

Keanekaragaman jenis kupu-kupu yang hidup di kawasan Bantimurung khususnya di Resort Pattunuang sekarang menjadi sangat terancam karena adanya pembangunan jembatan by-pass secara besar-besaran. Hilangnya sebagian besar vegetasi juga menyebabkan kawasan karst menjadi rawan longsor sehingga membahayakan masyarakat yang bermukim di dalamnya. Sangat disayangkan bahwa kelestarian habitat kupu-kupu yang mendapat julukan "The Kingdom of Butterfly" harus lenyap karena pengelola Taman Nasional Bantimurung-Bulusaraung tidak mampu melibatkan masyarakat dalam upaya pelestarian kupu-kupu sehingga perburuan kupu-kupu yang dilakukan oleh berbagai usia (khususnya murid Sekolah Dasar) untuk keperluan komersil dapat ditekan. Perlu disadari bahwa kupu-kupu endemik Sulawesi Selatan mempunyai nilai ekonomis yang sangat tinggi sehingga menyebabkan terjadinya perburuan, penangkapan dan penjualan yang tidak terkendali. Hal ini menjadi salah satu ancaman serius selain terjadinya kerusakan habitat karena terjadi bencana alam.

Salah satu strategi konservasi kupu-kupu yang efektif dilakukan untuk masyarakat di daerah Resort Pattunuang dan sekitarnya adalah memberikan informasi cara pelestarian kupu-kupu secara sederhana dan mudah dilakukan. Beberapa contoh yang sederhana adalah : tidak menangkap kupu-kupu secara sembarangan, menanam tumbuhan penghasil bunga sebagai sumber nektar kupu-kupu (kembang pagoda, asoka dan kembang sepatu) serta menanam tumbuhan pakan yang dapat digunakan oleh kupu-kupu untuk meletakkan telur.

Secara garis besar, konsep nasional tentang penggunaan dan konservasi kupu-kupu Indonesia yang berhubungan dengan Resort Pattunuang mencakup tiga hal yakni: mempertahankan habitat kupu-kupu yang bernilai secara ekonomis walaupun belum dilindungi oleh Peraturan Pemerintah, memperbanyak studi tentang kupu-kupu yang dapat digunakan oleh peneliti dan masyarakat yang membutuhkan serta mendidik masyarakat dalam hal memanfaatkan kupu-kupu secara terus menerus dan lestari. Pemecahan masalah tentang menurunnya populasi kupu-kupu di Resort Pattunuang dapat diraih dengan adanya dukungan Pemerintah berupa kerjasama dengan Perguruan Tinggi untuk membina masyarakat melalui pengenalan kupu-kupu untuk murid sekolah serta pelatihan konservasi kupu-kupu di habitatnya.

\section{KESIMPULAN}

Berdasarkan kegiatan yang telah dilakukan maka kesimpulan yang dapat diambil adalah : 1) kupukupu yang ditemukan di Resort Pattunuang sebanyak 20 individu terdiri dari 6 jenis yang berasal dari famili Papilionidae dan Nymphalidae; 2) berdasarkan nilai Indeks Shannon-Wiener untuk semua jenis kupu-kupu berada dalam kriteria sangat rendah $(\mathrm{H}<1)$ dan 3) sebanyak $57.3 \%$ murid Kelas 5 SDN 129 Inpres Bantimurung telah mengenal jenis kupu-kupu dan $28.8 \%$ dari anak-anak tersebut berprofesi sebagai penangkap kupu-kupu.

\section{DAFTAR PUSTAKA}

Amran, A. (2002). Potensi dan Sebaran Kupu-kupu di Kawasan Taman Wisata Alam Bantimurung. Workshop Pengelolaan Kupu-kupu Berbasis Masyarakat. Bantimurung, 5 Juni 2002. 
Braby, M. F. (2000). Butterflies of Australia: Their Identification, Biology and Distribution. CSIRO Publishing Victoria, Australia.

Dishut, (2003). Informasi Kawasan Konservasi : Potensi Kupu-kupu di Wilayah Kerja Balai KSDA Sulawesi Selatan I. Departemen Kehutanan Dirjen Perlindungan Hutan dan Konservasi Alam BKSDA Sulawesi Selatan.

Kristensen, N. P., Naumann, I. D., Came, P.B and Lawrence, J. F. (1991). The Insects of Australia: A Textbook for Students and Research Workers. CSIRO, Melbourne University Press. Carlton Victoria, Australia.

Odum, E. P. (1993). Dasar-dasar Ekologi. Penerjemah: T. Samingan dan B. Srigandono. Yogyakarta: Gadjahmada University Press.

Peggie, D,. and Amir M., 2006. Practical Guide to The Butterflies of Bogor Botanic Garden. Published by Centre of Biology LIPI and Nagao Natural Environment Foundation Japan. $126 p$.

Peggie, D. (2011). Precious and Protected Indonesian Butterfly (Kupu-kupu Indonesia yang Bernilai dan Dilindungi). Bidang Zoologi, Puslit Biologi LIPI dan Nagao Natural Environment Foundation. 72 hal.

Peggie, D. ( 2014). Mengenal Kupu-kupu. Pandu Aksara Publishing. 78 hal.

Pellet, J., Bried, J. T., Parietti, D,. Gander, A., Heer, PO,. Cherix, D and Arlettaz, R. ( 2012). Monitoring Butterfly Abundance:Beyond Pollard Walks. PLoS ONE 7(7):e41396. doi:10.1371/journal.pone.0041396.

Pustekkom. ( 2005). Perdagangan Satwa Liar. http://www.idkf.bogor.net/Perdagangan_Satwa Liar (diakses tanggal 24 Desember 2016).

Salmah. S., Abbas, I., dan Dahelmi. ( 2002). Kupu-kupu Papilionidae di Taman Nasional Kerinci Seblat. Departemen Kehutanan dan Yayasan Kehati. 88 hal.

Soehartono, T., dan Mardiastuti. (2002). CITES Implementation in Indonesia. Nagao Natural Environment Foundation. Jakarta pp 173-187.

Soerjani, M., Kostermans, A. J. G. H., and Tjitrosoepomo, G. (1987). Weeds of Rice in Indonesia.Balai Pustaka, Jakarta. 716 hal.

Sri, NAN., Nurariaty, A., and Annie, P. S. (2014a). The Potential of Flowering Weeds as Refugia for Predatory Insects at Bantimurung-Bulusaraung National Park, South Sulawesi. International Journal of Tropical Crop Science 1(2):25-29.

Sri, NAN., and Syatrawati. (2014b). A Preliminary Study of Graphium androcles Boisduval (Lepidoptera: Papilionidae) in Bantimurung-Bulusaraung National Park, South Sulawesi. Poster Presentation in SUIJI International Symposium and Seminar. Hasanuddin University, 13 - 15 September 2014.

Sri, NAN., Annie, P. S., Nurariaty, A., dan Amran, A. (2015). Beberapa Aspek Biologi Larva Kupu-kupu Raja Troides helena Linnaeus (Lepidoptera: Papilionidae) yang Diberi Makanan Buatan.[Disertasi]. Program Pascasarjana Universitas Hasanuddin, Makassar. 68 hal.

Suana, M. (2007). Hama Penting pada Tanaman Jagung. Kanisius, Yogyakarta.

Sutra, N. S. M., Dahelmi., dan Salmah, S. (2012). Spesies Kupu-kupu (Rhopalocera) di Tanjung Balai Karimun Kabupaten Karimun, Kepulauan Riau. Jurnal Biologi Universitas Andalas 1(1): 35-44.

van Steenis, CGGJ. (1988). Flora. PT. Pradnya Paramitha, Jakarta, Indonesia. 495 hal. 